"Prediction of the economic cost of individual long-term care in the Spanish population" 


\section{$\bigoplus_{\circledast}|\mathrm{R}| \mathrm{E}|\mathrm{A}|$}

Institut de Recerca en Economia Aplicada Regional i Pública

Research Institute of Applied Economics

\section{Universitat de Barcelona}

Av. Diagonal, $690 \bullet 08034$ Barcelona

WEBSITE: www.ub.edu/irea/•CONTACT: irea@ub.edu

The Research Institute of Applied Economics (IREA) in Barcelona was founded in 2005, as a research institute in applied economics. Three consolidated research groups make up the institute: AQR, RISK and GiM, and a large number of members are involved in the Institute. IREA focuses on four priority lines of investigation: (i) the quantitative study of regional and urban economic activity and analysis of regional and local economic policies, (ii) study of public economic activity in markets, particularly in the fields of empirical evaluation of privatization, the regulation and competition in the markets of public services using state of industrial economy, (iii) risk analysis in finance and insurance, and (iv) the development of micro and macro econometrics applied for the analysis of economic activity, particularly for quantitative evaluation of public policies.

IREA Working Papers often represent preliminary work and are circulated to encourage discussion. Citation of such a paper should account for its provisional character. For that reason, IREA Working Papers may not be reproduced or distributed without the written consent of the author. A revised version may be available directly from the author.

Any opinions expressed here are those of the author(s) and not those of IREA. Research published in this series may include views on policy, but the institute itself takes no institutional policy positions. 


\title{
Prediction of the economic cost of individual long-term care in the Spanish population
}

\author{
Catalina Bolancé, Ramon Alemany and Montserrat Guillén* \\ Department of Econometrics, RISC-IREA, University of Barcelona
}

September, 2010

\begin{abstract}
Pensions together with savings and investments during active life are key elements of retirement planning. Motivation for personal choices about the standard of living, bequest and the replacement ratio of pension with respect to last salary income must be considered. This research contributes to the financial planning by helping to quantify long-term care economic needs. We estimate life expectancy from retirement age onwards. The economic cost of care per unit of service is linked to the expected time of needed care and the intensity of required services. The expected individual cost of long-term care from an onset of dependence is estimated separately for men and women. Assumptions on the mortality of the dependent people compared to the general population are introduced. Parameters defining eligibility for various forms of coverage by the universal public social care of the welfare system are addressed. The impact of the intensity of social services on individual predictions is assessed, and a partial coverage by standard private insurance products is also explored. Data were collected by the Spanish Institute of Statistics in two surveys conducted on the general Spanish population in 1999 and in 2008. Official mortality records and life table trends were used to create realistic scenarios for longevity. We find empirical evidence that the public long-term care system in Spain effectively mitigates the risk of incurring huge lifetime costs. We also find that the most vulnerable categories are citizens with moderate disabilities that do not qualify to obtain public social care support. In the Spanish case, the trends between 1999 and 2008 need to be further explored.
\end{abstract}

\section{Introduction}

Anyone making retirement plans understands that ageing implies an increasing need of assistance from other persons. It is impossible to make an accurate prediction of how much long-term care (LTC) of a particular person is going to

${ }^{*}$ We acknowledge support from the Spanish Ministry of Science / FEDER ECO2010-21787. This article has been accepted for presentation at the International Conference on EvidenceBased Policy in Long-Term Care to be held at the London School of Economics, September 8-10, 2010. We acknowledge comments received from participants to the Barcelona Insurance and Risk Management Summer School, held in July 2010. Bolancé and guillén acknowledge support received from the ASA Research Fund. 
cost, because there are many factors influencing LTC cost estimation. These are current age, age of inception of dependence, duration and intensity of dependence. The age when one wants to know how much will be spent on LTC support is also a key factor. If the individual is very young, even if he or she has more time to accumulate savings, it is more difficult to predict the price of care services when he or she gets older. Costs of care are linked to the fluctuation of inflation and are connected to the economic dynamics. Another factor involved in the prediction of lifetime LTC costs is the extent to which the improvements in mortality rates are going to keep declining, as the increase in longevity in the last decades suggests. It is very likely that this trend will continue in the future. However, a question arises of whether living longer necessarily means that individuals will have a longer active life or whether, on the average, they will need support for a longer period of time (see also Wittemberg et al., 2002 and Guillén et al., 2007).

In this paper we have taken data from the Spanish Institute of Statistics on the prevalence of dependence by age and sex in Spain, namely, the percentage of people needing assistance to perform daily life activities. We have made projections on how much a person expects to spend on LTC support given his or her current age. Our analysis has focused on people aged 65 years or more. We have used actuarial principles, a hypothesis on inflation and have made separate estimates for men and women. We have used the definition of dependence that has been established by the current Spanish LTC public system of support. It was established in 2007, and, based on the definition, we distinguish three levels of intensity of dependence.

We have used data on the cost per unit of service and we have compared the estimates obtained in 1999 and in 2008. In nine years, changes have occurred in longevity, prevalence of dependence and in costs per unit. We have also tried to define which factors affect more strongly the changes in the cost distribution for a given cohort and the impact of the current LTC system on individual cost. This approach complements existing contributions to the discussion on the role of public and private LTC insurance by Feder et al. (2007), Brown and Finkelstein (2008), de Crasties (2009) and Gleckman (2010).

Our results contribute to individual planning and also to the design and reshaping of the current public LTC system in Spain. We also find empirical evidence of the effect of the public system on the risk beard by individual and the role that the development of private insurance market could play in this context (see, Kessler, 2008, Guillén and Pinquet, 2009, Pinquet et al., 2009 and 2010).

\section{The Spanish LTC public system}

In December 2006 the Spanish parliament approved the so called Law of Dependence, which was enforced in 2007. The law established a public LTC system and granted new rights to citizens in need of personal assistance. The law was recognized as a fourth pillar to the Spanish welfare system. Since then, the Spanish general budged has assigned increasing levels of funds for citizens needing LTC, and those funds have been set independently of public health funds.

In the new Spanish law, the concept of dependence is defined as "a permanent state of a person, as a result of ageing-related processes, illness o disability and 
linked to the absence or loss of physical, intellectual or sensorial autonomy that requires the assistance of a third person or support of any kind to perform basic daily life activities, or, in the case of people with intellectual disorders or mental illness, of other types of help for personal autonomy". The type of support that is guaranteed to any individual that is recognized to be dependent by this legal framework is not fully clear. Dependents can receive cash or service, but, even if priority has been given to service provision, most citizens currently prefer to receive cash.

Before the law has been passed, several forms of social protection have already existed in Spain. There were programs and social services for the elderly such as a network of public residences, day centers, food and care services, and similar facilities. It was mainly the local authorities and NPOs who played an active role in providing care to dependent people, mostly elderly. Citizens with little economic resources, living alone and in need of LTC were a priority, but there was no specific subsidy linked to the need of LTC for which citizens could apply. In fact, the public health system was effectively providing assistance to people in need of LTC who had no other resources, but this created a burden for medical facilities and implied an inefficient use of hospitals.

The new LTC public system set up in Spain in 2007 recognizes the right to receive support in case of dependence and puts strong emphasis on the need to assist, rather than just on disability or handicap. However, the Spanish budged allocated to LTC is among the most limited budgets in Western Europe, which means that even after the reform the public system does not cover all social protection needs connected to LTC is a sufficient way. According to Eurostat, in 2007 LTC expenditure in Spain was $0.74 \%$ of its GDP. Since the public LTC system was implemented in Spain, in general the society is deceived because of insufficient funds (see more information on EU countries in Holdenrieder, 2006, Solé-Auró and Crimmins, 2008, Fernandez et al. 2009 and Reimat, 2009). A strong advertisement campaign following the enforcement of the law created general awareness of the problems, but it also reinforced the role of the state as a strong safety net that slowly seems to be weakening.

The Spanish system is based on the principle of universality, equity and nondiscrimination. There are three levels of public responsibility for protection: minimum (general in Spain), enhanced (by an agreement between the central government and a given regional government) and supplementary (provided only by the regional government). A Territorial Council has been created in order to lower the discrepancies or inconsistencies in different regional autonomous communities. The system is funded by the general budged, but the law mentions the possibility of establishing means-tested co-payments, which have not yet been implemented.

One of the key issues in any LTC protection system is how to define the level of needs requiring support, that is, how to classify any individual applying for support into one group. This is usually done by means of a scale. Once the applicant's situation has been assessed by experts, he or she is either assigned to one of the three possible degrees of dependence or denied eligibility.

A scale called BVD (Baremo de Valoración de la Dependencia) has been legally established in Spain. The scale measures an individual's inability to perform daily life activities by means of a scale from 0 to 100 points. More information on the items included in the BVD is provided in the next section. The scale used in Spain puts a lot of emphasis on the intensity of support needed 
and the tasks for which assistance is required. In fact, the system has already been changed after the first three years and still there are doubts that it is consistently being applied by all regions. There is also a controversy regarding the role played by the evaluation of inability to perform instrumental daily life activities.

There are three severity levels in the Spanish LTC evaluation system (see, Esparza, 2010). A person is eligible in:

- Degree 1, if support is needed once a day (Level I: 25-40 points, Level II: 40-49 points)

- Degree 2, if assistance is to be provided two or three times per day (Level I: 50-64 points, Level II: 65-74 points)

- Degree 3, if assistance is demanded several times during the day (Level I: 75-89 points, Level II: $90+$ points)

Once an individual becomes eligible, he or she receives a personalized plan and can choose between assistance in kind or in cash, if it he or she prefers to be cared at home and this is indeed possible. Not all degrees and levels are funded. According to the reform, public funding was expected to gradually expand until 2016, depending on the available budged. Today only those having dependence level with severity of degree 2 or more are eligible. It is likely that budget restrictions will hinder the full implementation of the law at all levels of dependence, and that the categorization of dependence entails some level of moral hazard. Monthly allocations of funds for 2009 are shown in Table 1.

Table 1: LTC subsidy in Spain in 2009

Monthly maximum $(\text { minimum })^{(a)}$ allocation in euros

\begin{tabular}{lcccc}
\hline \multicolumn{6}{c}{ Degree and level } & Service & Family care ${ }^{(b)}$ & Personal assist. \\
\hline Degree 3 & Level II & $833.96(266.57)$ & 520.69 & 833.96 \\
Degree 3 & Level I & $625.47(181.26)$ & 416.98 & 625.47 \\
Degree 2 & Level II & $462.18(103.20)$ & 337.25 & \\
Degree 2 & Level I & $401.20(70.70)$ & 300.90 & \\
(a) The minimum amount that a person in that level should receive \\
(b) An additional sum of 162.49 euros is assigned for training and social security con- \\
tribution of the care worker
\end{tabular}

Table 1 indicates that someone who is eligible to receive LTC support from the public system can obtain up to 833.96 euros in cash as a monthly payment for the services received or 520.69 euros monthly for family care, if he prefers that relatives take care of him. In that case, an extra sum of 162.49 euros is given monthly to cover the social security taxes, and the training and education of the person that is employed as the family care-giver.

The maximum public support allowance is gradually lowered depending on the severity level of dependence. Currently, the minimum possible allowance is 70.70 euros monthly for people with a severity degree 2, at level I. We should note that once a person is placed into one of the above categories (except for the highest level), if there are signs of deterioration, he or she can apply again to be reclassified. 


\section{LTC cost of service in Spain}

In order to calculate lifetime LTC costs we have made realistic assumptions about the cost of services rather than taking the public LTC maximum or minimum allocations. Therefore, we have calculated an average cost of care in Spain as shown in Table 2. From these figures we can see that the cost of an hour of care at home has increased by $52.40 \%$ from 1999 to 2008 , which is above cumulated inflation ${ }^{1}$. The yearly price of day centers has also increased substantially from 1999 to 2008. The price of residence for dependent people increased $30.78 \%$ from 1999 to 2003, but since then the price has not raised much. The service called tele-assistance is provided by means of a device based on telecommunications, that alerts medical centers or family members when the carrier pushes a button. The cost of tele-assistance in 2008 was lower than in 1999. This is certainly due to technological innovations and the widespread use of this system.

From the data in Table 2, we have calculated an average estimated cost of care for individuals with dependence of degree 1 (moderate dependence), degree 2 (severe dependence) and degree 3 (full dependence), under two possible alternatives of care. For non-dependent we assume that the annual cost of care is zero.

Table 3 displays the information about the average yearly cost of care in 2008 according to the severity level and the type of provided care. For our lifetime LTC cost predictions, we have taken the first set of costs. Under this alternative of care, the cost is different for every severity level and type of care is defined by severity level. The average yearly cost of service for people with moderate dependence is $13,917.45$ euros, because they receive three hours of care at home daily. The average yearly cost of service for people the with severe dependence is $12,512.47$ euros, because they are cared at a day center and get one hour of care at home daily. It is a bit counterintuitive that those with severe dependence have an average yearly LTC cost lower than those with moderate dependence. However, we have based our cost estimations on experts' opinions. They recommend to extend the at home care as much as possible in order to prolong the moderate state of dependence and deter the progression in loss of autonomy. Individuals that stay at home are in general more autonomous than those who attend a day care centre. Finally, residential care is the recommended alternative for people with the most severe level of dependence. A residence for a dependent person costs 17,295.60 euros per year. All prices only include the cost of care, not the cost of room and board.

The second part of Table 3 shows the estimated average cost of care if the person stays at home. We show those figures in order to provide evidence that home care for dependent people is much more expensive due to the intensity of care needed.

\footnotetext{
${ }^{1}$ IPCA index as INEbase for 1999M06 is 82.29 and for 2008M06 it equals 112.3. So cumulated inflation from 1999 to 2008 is equal to $36.47 \%$
} 
Table 2: LTC cost in Spain per type of care from 1999 to 2008 in euros

\begin{tabular}{|c|c|c|c|c|c|c|}
\hline \multirow[b]{2}{*}{ Type of LTC } & \multirow[b]{2}{*}{1999} & \multirow[b]{2}{*}{2003} & \multirow[b]{2}{*}{2008} & \multicolumn{3}{|c|}{ Percent difference } \\
\hline & & & & 1999-2003 & 2003-2008 & 1999-2008 \\
\hline $\begin{array}{l}\text { Public service: Home care (per } \\
\text { hour) }\end{array}$ & 8.34 & 9.73 & 12.71 & $16.67 \%$ & $30.63 \%$ & $52.40 \%$ \\
\hline Public service: Teleassistance & 273.53 & 242.23 & 253.92 & $-11.44 \%$ & $4.83 \%$ & $-7.17 \%$ \\
\hline $\begin{array}{l}\text { Public service: Day care centre } \\
\text { for dependent }\end{array}$ & $5,510.49$ & $6,625.2$ & $7,873.32$ & $20.23 \%$ & $18.85 \%$ & $42.88 \%$ \\
\hline Residence for dependent & $12,870.34$ & $16,832.30$ & $17,295.6$ & $30.78 \%$ & $2.75 \%$ & $34.38 \%$ \\
\hline Residence for non-dependent & & & $15,531.00$ & & & \\
\hline
\end{tabular}

Table 3: Average LTC cost in Spain in 2008 in euros

Combined home and external care service

\begin{tabular}{lcc}
\hline Severity level & Type of care & Yearly cost \\
\hline Degree 1 & 3h/day home care & $13,917.45$ \\
Degree 2 & Day centre and 1h/day home care & $12,512.47$ \\
Degree 3 & Residential care & $17,295.60$ \\
\hline \multicolumn{3}{c}{ Exclusively at home care } \\
\hline Severity level & Type of care & annual cost \\
\hline Degree 1 & 3h/day home care & $13,917.45$ \\
Degree 2 & Day centre and 1h/day home care & $37,113.20$ \\
Degree 3 & Residential care & $64,948.10$ \\
\hline
\end{tabular}

\section{The data}

We have taken data collected in 1999 and in 2008 by the Spanish Institute of Statistics (INE, Instituto Nacional de Estadística). The first survey had been conducted before the public LTC system was reformed in Spain. The survey was called EDDES 1999, which stands for Survey of Disabilities, Dependence and Health Status. This survey provided information on the general population that used to have initial estimates of the potential number of people that would be eligible. The sample was of a significant size, since 220,000 people were interviewed by means of an extensive questionnaire. Individuals with at least one disability provided information on the type of disability, age at onset, type of support needed and received (Bermúdez et al., 2009).

In 2008, a second large scale survey was conducted by INE, and it was called EDAD, which stands for Survey of Disabilities, Personal Autonomy and Situations of Dependence. This survey was not a follow-up study or a panel study, since a new sample was selected. The aim of the 2008 survey was to determine the disability and level of dependence of Spanish citizens one more time, and to learn more about the social network surrounding persons with disabilities. The structure of that survey was very similar to the previous one. About 260,000 people were interviewed.

In the survey EDAD 2008 there were 22,795 respondents with at least one difficulty to perform DLAs (daily life activities). The estimated total number of people in Spain with at least one disruption in DLAs is obtained with the inverse of the sample weight, which gives an estimate of 3.85 million people reporting difficulty in performing at least one DLA. This corresponds to a prevalence of 
about 85.5 per thousand people in the total population.

There are 26 variables in the survey questionnaire that inquire about each DLA that are then used in the BVD scale to measure dependence severity. When a respondent indicates that he has a difficulty to perform a specific DLA, then he or she must indicate whether the difficulty is moderate, severe or total. According to the law, we assigned a coefficient value of 0.90 for moderate difficulty, 0.95 for severe difficulty and 1.00 for total inability to perform that particular DLA.

We also identified individuals with disorders when performing IDLAs (instrumental daily life activities), because the BVD scale has some particular coefficients for those individuals who have a difficulty in performing tasks due to some cognitive or intellectual challenges. Inability to perform any of the following four activities is considered sufficient to have a disorder in IDLA: difficulty to pay attention when listening or looking, significant difficulty to learn to read, to write, to count (or calculate), to copy or to learn to handle devices, major difficulty to perform simple tasks without help or supervision and major difficulty to perform complex tasks without assistance and without supervision.

The number of points given by the BVD scale is obtained by adding the severity coefficient times the weight assigned on the scale to that particular task for every existent ADL or IADL. The current weights (as approved on July 12th, 2010) are given in the Appendix.

\section{The actuarial estimate of the average lifetime LTC cost}

We use the notation that is common in actuarial science. Let $p_{x}$ be the probability that someone alive at age $x$ survives to age $x+1$, then $q_{x}=1-p_{x}$ is the probability that an individual aged $x$ dies before he or she reaches age $x+1$.

In this work, we have assumed that the probability of dying does not change with the dependency level of an individual. This assumption is controversial, but we have no data to make realistic hypothesis on whether people needing long-term care have a larger or smaller probability of dying at a given age, than someone that does not need care (some extensions can be found in Crimmins et al., 1994, Albarran et al., 2005 and Cairns et al., 2008).

We call $t_{x}$ the overall prevalence rate of dependent individuals at age $x$. When we specify the prevalence of those needing care in every level of severity, which we call state, we specify a superindex. So, $t_{x}^{(1)}, t_{x}^{(2)}$ and $t_{x}^{(3)}$ correspond respectively to the percentage of those people that are in state $G 1, G 2$ or $G 3$ among all people at age $x$. States $G 1, G 2$ and $G 3$ correspond to moderate, severe and full level of dependence in our context. It holds that:

$$
t_{x}=t_{x}^{(1)}+t_{x}^{(2)}+t_{x}^{(3)}=\sum_{k=1}^{3} t_{x}^{(k)}
$$

and we denote by $t_{x}^{(0)}=1-t_{x}$ the prevalence rate of non-dependent.

Let $l_{x}$ be the number of survivors at age $x$. For every age, we have that:

$$
l_{x+1}=\left(1-q_{x}\right) \cdot l_{x} .
$$


Those people that are alive at age $x$ can be classified, which means that they are either non-dependent or belong to states $G 1, G 2$ or G3. The number of people in every state can be calculated as follows:

$$
l_{x}^{(j)}=t_{x}^{(j)} \cdot l_{x}, j=0,1,2,3 .
$$

So, we know that:

$$
l_{x}=l_{x}^{(0)}+l_{x}^{(1)}+l_{x}^{(2)}+l_{x}^{(3)}=\sum_{j=0}^{3} l_{x}^{(j)} .
$$

As a result, the total number of years lived by all individuals in age $x$ can be expressed as the sum of the total number of years lived by the individuals in each state level as:

$$
T_{x}=\sum_{i=x}^{\infty} l_{i}=\sum_{i=x}^{\infty}\left(l_{i}^{(0)}+l_{i}^{(1)}+l_{i}^{(2)}+l_{i}^{(3)}\right)=T_{x}^{(0)}+T_{x}^{(1)}+T_{x}^{(2)}+T_{x}^{(3)} .
$$

From the previous expression, we obtain the well-known concept of life expectancy from age $x$ as the sum of four terms, which we can call the disaggregation of life expectancy Sullivan, 1971 and Chiang, 1984):

$$
e_{x}=\frac{T_{x}}{l_{x}}=\frac{T_{x}^{(0)}}{l_{x}}+\frac{T_{x}^{(1)}}{l_{x}}+\frac{T_{x}^{(2)}}{l_{x}}+\frac{T_{x}^{(3)}}{l_{x}}=e_{x}^{(0)}+e_{x}^{(1)}+e_{x}^{(2)}+e_{x}^{(3)} .
$$

Expression (2) shows that life expectancy at age $x$ can be decomposed in dependency-free life expectancy $e_{x}^{(0)}$, and life expectancy from age $x$ in states $G 1, G 2$ and $G 3$, respectively.

Let $C_{x}$ be the random variable that represents the remaining lifetime cost of long-term care for an individual aged $x$. When we want to compute the mathematical expectation of $C_{x}$, namely $E\left(C_{x}\right)$, we need $c^{(1)}, c^{(2)}$ and $c^{(3)}$, which correspond to the current annual average cost of care of those individuals in the severity levels $G 1, G 2$ and $G 3$, respectively. We assume that the cost of care for a non-dependent is zero. Then it follows that:

$$
\begin{aligned}
E\left(C_{x}\right) & =\frac{\sum_{i=x}^{\infty}\left(c^{(1)} \cdot l_{i}^{(1)}+c^{(2)} \cdot l_{i}^{(2)}+c^{(3)} \cdot l_{i}^{(3)}\right)(1+r)^{i-x}}{l_{x}} \\
& =\frac{\sum_{i=x}^{\infty}\left(c^{(1)} \cdot l_{i}^{(1)}\right)(1+r)^{i-x}}{l_{x}}+\frac{\sum_{i=x}^{\infty}\left(c^{(2)} \cdot l_{i}^{(2)}\right)(1+r)^{i-x}}{l_{x}}+\frac{\sum_{i=x}^{\infty}\left(c^{(3)} \cdot l_{i}^{(3)}\right)(1+r)^{i-x}}{l_{x}} \\
& =E\left(C_{x}^{(1)}\right)+E\left(C_{x}^{(2)}\right)+E\left(C_{x}^{(3)}\right),
\end{aligned}
$$

where $r$ is the annual rate of inflation. Further extensions, needing more assumptions are presented in Haberman and Pitacco (1999).

\subsection{Smoothing the prevalence of dependent people age $x$ by severity level}

We denote by $f_{x}^{(k)}$ the raw percent of individuals aged $x$ with a dependency level indexed by $k=1,2,3$. Remember that in our application male and female are calculated separately, but here we do not complicate notation to show that the prevalence rates differ for men and women. 
Usually raw estimates of the prevalence rates are obtained from surveys and therefore, sampling error introduces some fluctuations as a prevalence is needed for every age group. Especially in small cohorts, i.e. above 90 years, since the population is small, survey estimates do not show increasing shape, as it should be expected. In order to smooth the sampling variability, we have computed smoothed rates as follows:

$$
t_{x}^{(k)}=\sum_{i=65}^{105} \frac{K\left(\frac{i-x}{b_{n}^{(k)}}\right) f_{i}^{(k)}}{K\left(\frac{i-x}{b_{n}^{(k)}}\right)},
$$

where $b_{n}^{(k)}$ is the smoothing parameter, $n$ is the number of smoothing points, in this case $105-65+1=41$, and $K(\cdot)$ is the kernel function. In our application we have used a Gaussian kernel, so $K(\cdot)$ corresponds to the density of a $\operatorname{Normal}(0,1)$ random distribution. The value of the smoothing parameter that we have used is $b_{n}^{(k)}=s_{65}^{(k)} n^{-\frac{1}{5}}$, where $s_{65}$ is the standard deviation estimated of age in the group 65 to 105 . Finally, the prevalence rate of non-dependent is calculated as $t_{x}^{(0)}=1-\left(t_{x}^{(1)}+t_{x}^{(2)}+t_{x}^{(3)}\right)$ for consistency.

\section{Estimating the lifetime LTC cost distribution at a given age}

In order to estimate the LTC cost distribution we assume an initial population of size $N$ aged $x$. To determine on a yearly basis what will be an individual's dependence level in the following year, we assume that the individual will move to the degree of dependence that immediately follows his or her current status. Therefore, in a period of one year a dependent individual may either die or continue living in the same situation, or he or she may experience a deterioration of the condition to a higher level on the scale of dependence severity. Individuals in the state $G 3$ cannot move to any higher level on the scale of severity. We also assume that individuals cannot recover and so, we do not consider that individuals on any dependence level can move down the scale of dependence. The calculation process goes through three stages described below:

- Step 1: We assign a proportional number of individuals from the initial population to the four states: non-dependent, G1, G2 or G3. For that purpose we use the smoothed prevalence rates calculated before as $t_{x}^{(0)}$, $t_{x}^{(1)}, t_{x}^{(2)}$ and $t_{x}^{(3)}$. We obtain $N^{(0)} \approx t_{x}^{(0)} \cdot N, N^{(1)} \approx t_{x}^{(2)} \cdot N, N^{(2)} \approx t_{x}^{(2)} \cdot N$ and $N^{(3)} \approx t_{x}^{(3)} \cdot N$. Note that rounding is necessary in oder to obtain a natural number for $N^{(k)}, k=0,1,2,3$ and that we have a restriction so that $N=\sum_{k=0}^{3} N^{(k)}$. We generate a vector of $N$ components, one for every individual in the initial population. In the first $N^{(0)}$ components, we assign a zero, which indicates that the corresponding individual is nondependent. Then from component $N^{(0)}+1$ to $N^{(0)}+N^{(1)}$ we assign value 1 , meaning that those individuals belong to level G1. From $N^{(0)}+N^{(1)}$ to $N^{(0)}+N^{(1)}+N^{(2)}$ we assign value 2 , thus indicating that those individuals belong to level $G 2$ and, finally, from component $N^{(0)}+N^{(1)}+N^{(2)}$ to $N$ we assign value 3 , as the rest of individuals belong to group $G 3$. 
- Step 2: Using the probability of death, we create a binary variable for each individual. This variable takes value one if the individual aged $x$ dies before reaching age $x+1$ and the variable equals zero if the individual survives. We calculate the number of individuals that die in each state (non-dependent, G1, G2 and G3). The number of deaths in each case is equal to the probability of death $q_{x}$ times the number of people aged $x$ in each severity level. This product is non-integer in general, so we need to round and make sure that the sum of deaths is equal to the rounded sum of expected total deaths, which we call $m_{x}$. In fact, $m_{x}$ is equal to the probability of dying at age $x, q_{x}$, times the total number of individuals at that age $l_{x}$, or $N$ in the initial simulated population size. Once the number of dead individuals in each state is computed, the initial vector is reformulated: The number of survivor at age $x+1$ is then equal to $l_{x+1}=N-m_{x}$.

- Step 3: With the individuals that have survived up to age $x+1$, the distribution of individuals among the different severity levels is done with the corresponding smoothed rates at age $x+1$. Again, rounding is necessary to obtain integer values. Therefore, $l_{x+1}^{(0)}=t_{x+1}^{(0)} \cdot l_{x+1}, l_{x+1}^{(1)}=t_{x+1}^{(2)} \cdot l_{x+1}$, $l_{x+1}^{(2)}=t_{x+1}^{(2)} \cdot l_{x+1}$ and $l_{x+1}^{(3)}=t_{x+1}^{(3)} \cdot l_{x+1}$.

With the new distribution along severity levels in step 3, we set $N^{(0)}=l_{x+1}^{(0)}$, $N^{(1)}=l_{x+1}^{(1)}, N^{(2)}=l_{x+1}^{(2)}$ y $N^{(3)}=l_{x+1}^{(3)}$. Step step 2 and then step 3 are iterated but substituting $N$ by $\left(N^{(0)}+N^{(1)}+N^{(2)}+N^{(3)}\right)$ until the maximum age is reached or until no more individuals have survived.

Once the process is carried out, we calculate the cost incurred by every individual of the initial cohort of $N$ people. A variable called $d_{i j}$ takes values $0,1,2$ o 3 depending on the $i$-th individual state level at age $j$. Then, the lifetime cost for individual $i$ at age $x$, which we call $c_{i x}$, is equal to the sum of the cost he incurs at later ages, which in turn depends on the state he is at any given age. Then, we can write:

$c_{i x}=\sum_{j=x}^{\infty}\left(0 \cdot I\left(d_{i j}=0\right)+c^{(1)} I\left(d_{i j}=1\right)+c^{(2)} I\left(d_{i j}=2\right)+c^{(3)} I\left(d_{i j}=3\right)\right)(1+r)^{j-x}$,

where $I(\cdot)$ is the indicator function that takes value 1 if the condition in parenthesis is true.

A histogram of the previous values for all individuals that are alive at age $x, l_{x}$, provides an estimate of the random distribution of lifetime LTC costs from age $x$. The mean of (5) must be approximately equal to the mathematical expectation calculated using the method in the previous section. The randomness of the LTC lifetime cost from age $x$ random variable, comes from the fact that individual trajectories are not all equal. So, some individuals may die very young, incurring no care costs and some others may live many years and may need care for a long period.

Given that computation is fast, this distribution estimation method is easily implemented. Unfortunately if the initial cohort is now too big, then the distribution estimate has many fluctuations, whereas if it is larger, then computation slows down due to the size of vectors. In our analysis, we used $N=100,000$ initial individuals. 


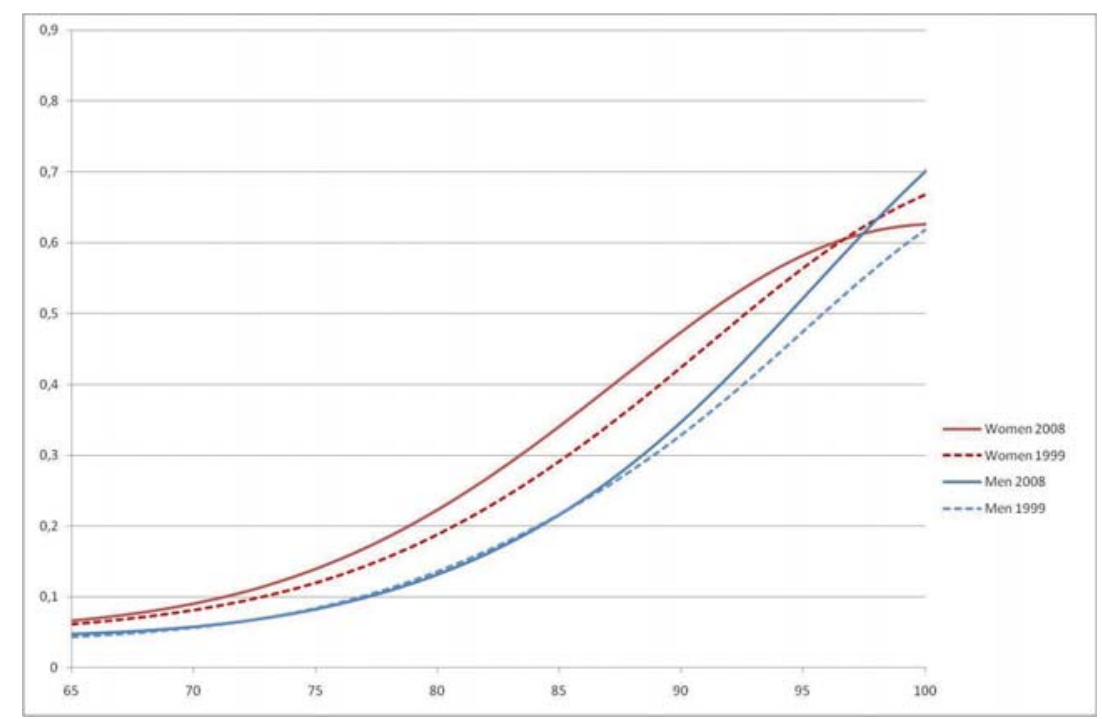

Figure 1: Percentage of dependents at each given age by gender in Spain, 1999 and 2008

The procedure described above is not fully random. Randomness should be induced if every individuals would have a random probability of death and random transition rates from one state to another. Then the natural statistical approach in order to incorporate variability of death and transition rates would be to design a Monte Carlo simulation. It would imply using random distributions for the probability of death and random distributions for the transition probabilities between states. Repetitions would then reflect randomness of lifetime cost due to individual heterogeneity and also due to parameter uncertainty or estimation error.

\section{Results}

Figure 1 shows the smoothed rate of prevalence of dependence in 1999 and 2008, where we have considered all states together.

Figures 2 and 3 disaggregated life expectancy in 1999 and 2008 from different starting ages separately for Spanish men and women. We can see that there is a difference between men's and women's life expectancy. The plots also show that life expectancy from ages above 65 has increased in 2008 as compared to 1999 , both for men and women. This phenomenon indicates that longevity has increased noticeably in the past decade. Table 4 shows the numbers displayed in the above-mentioned Figures and we can then see disaggregated remaining life expectancy for some selected ages in 2008. The estimates for 1999 are shown in parenthesis. For instance, a man aged 65 in 2008 has a remaining life expectancy of 16.33 years and from that total, 14.58 years correspond to dependence-free life expectancy, 0.72 years on average correspond to moderate dependence, 0.47 to severe dependence and 0.56 to full dependence.

In Table 4 we can see that both for men and women, life expectancy in all states has increased between 1999 and 2008. There are two exceptions, since 


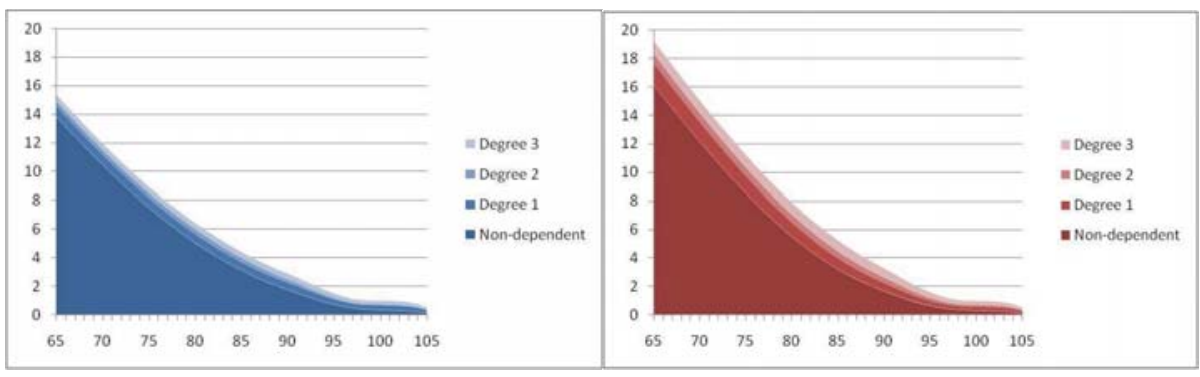

(a) Men

(b) Women

Figure 2: Disaggregated life expectancy in Spain, 1999

moderate dependence at ages 65 and 95 has slightly decreased for both men and women. From the results in Table 4 we conclude that longevity has increased in the past decade and also that expected life expectancy in a situation of dependence has generally increased too.

In order to see whether it is longevity or average duration in a dependence state that increases more, we have calculated the percentage of life-expectancy that corresponds to dependence-free life expectancy in 2008 and in 1999 (figures shown in parenthesis) for some selected ages and for men and women separately. The results can be found in Table 5 . In Table 5 we conclude that the proportion of years spent in a non-dependent state has diminished from 1999 to 2008 for all ages in Spain both for men and women. So, this means that average duration in a dependence stated has increased more than longevity in the past decade. There is an exception to this rule in centennial women, for whom this pattern changes and we do not know whether this is due to random fluctuations or to a stable result. The estimates indicate that centennial women have proportionally larger dependency-free life expectancy in 2008 than in 1999.

Our results show that the situation in Spain is that longevity increases while life-expectancy with dependence increases in all ages above 65 both for men and women. Simultaneously, dependence-free life expectancy has decreased in the past decade for all ages above 65 years. We do not explore the causes for those phenomena They can be the result of better medical therapies for dependent people that allow for better survival prospects. However, we conclude that since the cost of care is proportional to life expectancy in the dependence states, then the recent trends indicate that the total cost of LTC keeps increasing accordingly.

We have estimated the expected lifetime cost of LTC in dependence for individuals aged 65 years and above. Calculations have been made separately for men and women. Estimations are done for year 1999 and 2008, respectively, using data from the two official surveys carried out by the Spanish Institute of Statistics that have been described in a previous section. From each survey, the prevalence of dependent individuals in each severity level was obtained separately for men and women at age $\mathrm{x}$ and rates were smoothed. In our analysis 
Table 4: Life expectancy at given ages by gender in Spain in 2008 and 1999(in parenthesis

\begin{tabular}{lrrrrr}
\multicolumn{5}{c}{ Men } \\
From age & Non-dependent & Moderate & Severe & Full & Total \\
\hline 65 & $14.58(13.81)$ & $0.72(0.76)$ & $0.47(0.36)$ & $0.56(0.43)$ & $16.33(15.36)$ \\
70 & $11.11(10.45)$ & $0.66(0.71)$ & $0.45(0.35)$ & $0.56(0.43)$ & $12.78(11.93)$ \\
75 & $7.98(7.48)$ & $0.59(0.66)$ & $0.43(0.34)$ & $0.57(0.43)$ & $9.58(8.91)$ \\
80 & $5.35(5.03)$ & $0.52(0.62)$ & $0.42(0.32)$ & $0.60(0.43)$ & $6.89(6.40)$ \\
85 & $3.30(3.13)$ & $0.43(0.57)$ & $0.40(0.27)$ & $0.63(0.42)$ & $4.75(4.39)$ \\
90 & $1.81(1.76)$ & $0.31(0.51)$ & $0.36(0.19)$ & $0.64(0.41)$ & $3.13(2.87)$ \\
95 & $0.69(0.73)$ & $0.16(0.37)$ & $0.24(0.09)$ & $0.50(0.30)$ & $1.58(1.48)$ \\
100 & $0.27(0.36)$ & $0.08(0.33)$ & $0.17(0.04)$ & $0.47(0.26)$ & $0.98(0.98)$ \\
105 & $0.08(0.14)$ & $0.03(0.20)$ & $0.08(0.01)$ & $0.31(0.15)$ & $0.50(0.50)$ \\
\hline
\end{tabular}

Women

\begin{tabular}{lrrrrr} 
From age & Non-dependent & Moderate & Severe & Full & Total \\
\hline 65 & $16.35(16.15)$ & $1.51(1.53)$ & $1.07(0.68)$ & $1.27(0.86)$ & $20.19(19.23)$ \\
70 & $12.29(12.16)$ & $1.37(1.37)$ & $1.01(0.66)$ & $1.24(0.85)$ & $15.91(15.04)$ \\
75 & $8.60(8.56)$ & $1.20(1.18)$ & $0.93(0.62)$ & $1.20(0.84)$ & $11.94(11.20)$ \\
80 & $5.49(5.51)$ & $0.97(0.98)$ & $0.83(0.58)$ & $1.15(0.80)$ & $8.44(7.87)$ \\
85 & $3.18(3.22)$ & $0.72(0.76)$ & $0.69(0.51)$ & $1.05(0.73)$ & $5.64(5.23)$ \\
90 & $1.70(1.68)$ & $0.47(0.57)$ & $0.54(0.41)$ & $0.87(0.61)$ & $3.58(3.27)$ \\
95 & $0.70(0.65)$ & $0.22(0.34)$ & $0.31(0.24)$ & $0.50(0.36)$ & $1.73(1.58)$ \\
100 & $0.37(0.32)$ & $0.11(0.25)$ & $0.22(0.17)$ & $0.29(0.25)$ & $0.98(0.98)$ \\
105 & $0.20(0.14)$ & $0.05(0.14)$ & $0.13(0.09)$ & $0.12(0.13)$ & $0.50(0.50)$ \\
\hline
\end{tabular}

Table 5: Proportion of dependence-free life expectancy with respect to total remaining life expectancy at given ages by gender in Spain in 2008 and 1999(in parenthesis)

\begin{tabular}{lcc} 
From age & Men & Women \\
\hline 65 & $89 \%(90 \%)$ & $81 \%(84 \%)$ \\
70 & $87 \%(88 \%)$ & $77 \%(81 \%)$ \\
75 & $83 \%(84 \%)$ & $72 \%(76 \%)$ \\
80 & $78 \%(79 \%)$ & $65 \%(70 \%)$ \\
85 & $69 \%(71 \%)$ & $56 \%(62 \%)$ \\
90 & $58 \%(61 \%)$ & $47 \%(51 \%)$ \\
95 & $43 \%(49 \%)$ & $40 \%(41 \%)$ \\
100 & $27 \%(36 \%)$ & $37 \%(32 \%)$ \\
105 & $17 \%(29 \%)$ & $39 \%(28 \%)$ \\
\hline
\end{tabular}




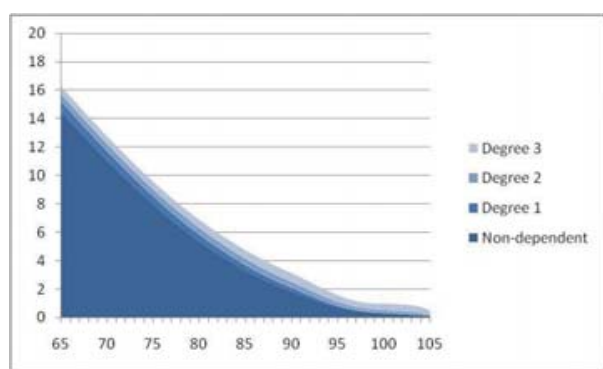

(a) Men

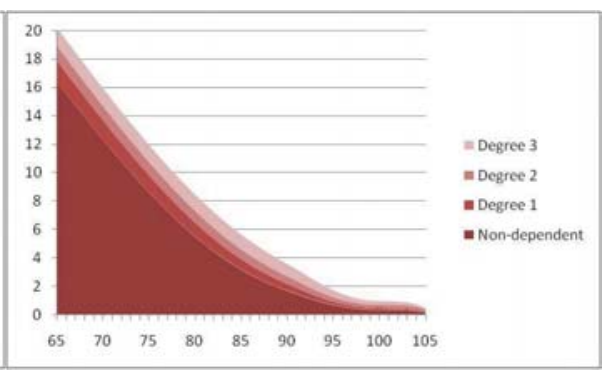

(b) Women

Figure 3: Disaggregated life expectancy in Spain, 2008

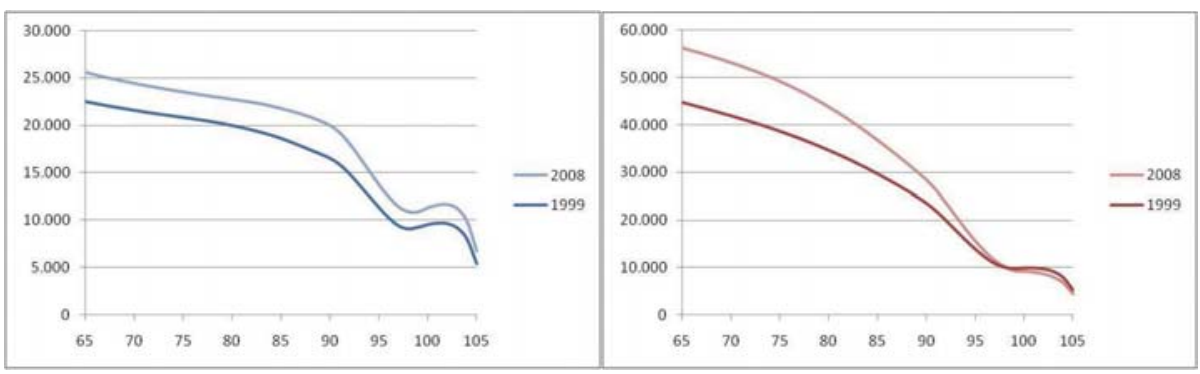

(a) Men

(b) Women

Figure 4: Estimated expected remaining lifetime LTC-dependence cost in Spain given current age in 1999 and 2008

we assimilated the need of LTC to the definition of dependence given by the Spanish regulation. This can be controversial because the number of people with disabilities that require some form of care is different from the number of dependent people as defined by the BVD. Our LTC cost estimation only refers to care for those who need support, because that's how dependence is defined by the Spanish regulations.

Survival probabilities are also taken from the official records of the Spanish Institute of Statistics, for the general population resident in Spain. In order to obtain the results expressed in (1), (2) and (3) we use raw mortality rates

The maximum age is 105 years, but since data on mortality is unreliable we assumed that from 99 the yearly probability of death is constant and it is set equal to 0.5 , both for men and women.

Figures $4 \mathrm{a}$ and $4 \mathrm{~b}$ show the estimated expected remaining lifetime LTC costs from every given age in 1999 and 2008, respectively for men and women.

By looking at Figure 4, we notice the gap between men and women. Due to longer life expectancy and greater prevalence of dependence, women expect to incur more LTC costs than men. We also see an expected cost increase between 1999 and 2008, which is partly due to inflation and partly due to the evolution of longevity and dependence prevalence. The first column of Table 6 shows the expected LTC cost for men and women in thousands of euros in 2008 and 1999 (figures shown in parenthesis) as calculated by the actuarial approach 
Table 6: Estimated expected remaining lifetime LTC in dependence individual cost in Spain given current age in 2008 and 1999(in parenthesis) in thousand euros

\begin{tabular}{lrrrr} 
& \multicolumn{2}{c}{ Men } & \multicolumn{2}{c}{ Women } \\
From age & LTC cost & Incr. 1999-2008 & LTC cost & Incr. 1999-2008 \\
\hline 65 & $25.6(22.5)$ & $14 \%$ & $56.3(44.8)$ & $26 \%$ \\
70 & $24.5(21.6)$ & $13 \%$ & $53.1(42.0)$ & $27 \%$ \\
75 & $23.5(20.9)$ & $13 \%$ & $49.2(38.7)$ & $27 \%$ \\
80 & $22.8(20.0)$ & $14 \%$ & $43.8(34.7)$ & $26 \%$ \\
85 & $21.8(18.7)$ & $17 \%$ & $36.8(29.7)$ & $24 \%$ \\
90 & $20.0(16.6)$ & $21 \%$ & $28.4(23.6)$ & $20 \%$ \\
95 & $13.8(11.4)$ & $21 \%$ & $15.7(13.9)$ & $12 \%$ \\
100 & $11.3(9.5)$ & $18 \%$ & $9.2(9.9)$ & $-7 \%$ \\
105 & $6.7(5.4)$ & $24 \%$ & $4.5(5.3)$ & $-16 \%$ \\
\hline
\end{tabular}

with an inflation evolution of $r=2 \%$ yearly. The expected LTC cost increase between1999 and 2008 is shown in the second column of Table 6 .

A man in Spain aged between 65 and 80 expects an average lifetime LTC cost of about 20 to 25 thousand euros. On the other hand, a woman aged 65 to 75 expects an average lifetime LTC cost about 50 thousand euros, which is double the expected cost for men of the same age. At age 90 the gap between men and women is smaller than in previous age groups, but it is still significant. A man aged 90 expects an average lifetime LTC cost of 20 thousand euros, while a woman expects to spend 28 thousand euros. These results do not mean that a man aged 65 in 2008 can estimate that in twenty-five years, when he becomes 90 he will have an expected cost of 20 thousand euros. Deferring expenditure by twenty-five years would imply that he will need to account for inflation, longevity increase and the evolution of dependence prevalence. We call this the cost prediction dynamics, since our forecast needs to take into consideration the trends of all these three factors together.

A simple calculation using the gap between 1999 and 2008, indicates that if the average cost increases is about the same as in the past, then expected lifetime LTC cost would increase about $21 \%$ every nine years at age 90 . At that age, the percent increase is about the same, but at earlier ages, the increase is larger. For instance, a woman that is 38 year old in 2008, if all things stay the same, should expect lifetime LTC costs at age 65 to be have increasing by $26 \%$ every nine years, so she should estimate her average lifetime LTC costs to be 113 , $\left(56.3 \times 1.26^{3}\right)$, thousand euros. A increase of $26 \%$ every nine years means roughly that the initial estimated amount doubles every three decades approximately, while an increase of $15 \%$, which corresponds to the evolution experienced by the expected lifetime LTC costs for men between 1999 and 2008, means that the amount doubles in about five decades.

Our analysis includes the approximation of the estimation of the LTC cost of dependence distribution. The dependence prevalence rates used in the simulation of individual costs are the same as the ones used in the previous section. 


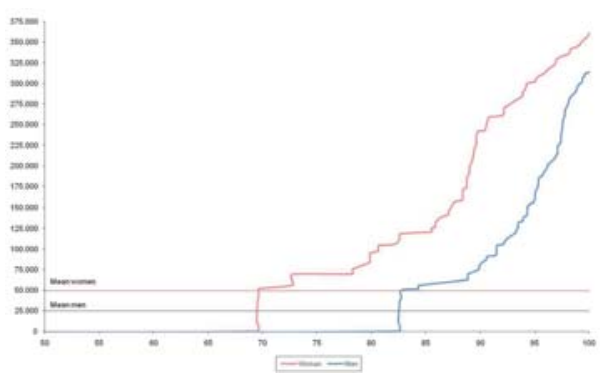

(a) In 1999

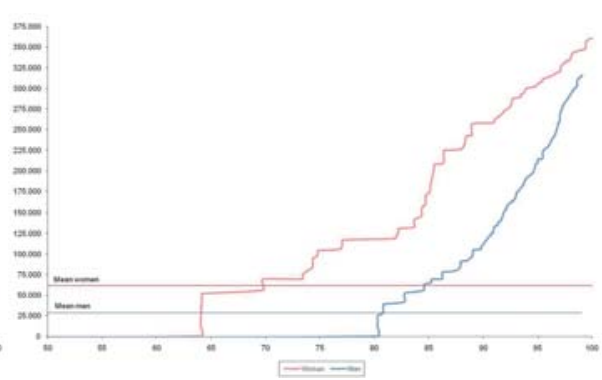

(b) In 2008

Figure 5: Distribution of LTC costs of dependence in Spain for 65 year old

Figure 5 shows the quantile plot for 1999 and 2008 of the lifetime LTC cost estimated distribution for men and women aged 65 years.

From the quantile plots shown in Figure 5 we see that the majority of individuals aged 65 do not incur any LTC costs associated to dependence, while a small percentage can have to spend large amounts of money in LTC services.

The quantile plot indicates that the LTC lifetime cost distribution is very asymmetric. Under this kind of behaviour, when most citizens do not have any expenditure while others can have huge economic losses, risk pooling is optimal. Sharing the cost of LTC by means of public programmes or private insurance, or a combination of the two, protects the small proportion of individuals who suffer high costs from having to pay them. This sort of cost distribution reminds of the so called catastrophic risks, where very unlikely events may cause large economic losses.

Table 7 shows some quantiles from the LTC cost distribution. Both in 2008 and in 1999, we estimate that more than $60 \%$ of the population at age 65 has no lifetime cost on LTC associated to dependence, $80 \%$ of men still have no cost, while $90 \%$ would spend less than 111.8 thousand euros over lifetime. Conversely, the quantile interpretation means that among men aged 65 years, $10 \%$ have an estimated lifetime cost above 111.8 thousand euros, and in the $5 \%$ worst cases, we estimate that those men will require more than 210.9 thousand euros over their entire lifetime. There is a very small minority of $1 \%$ individuals that have an estimated lifetime cost above 314.6 thousand euros.

In real, aggregated terms this means that, since there were 201,960 men in Spain aged 65 in 2008, over 2, 000 men aged 65 have an estimated lifetime LTC cost above 300 thousand euros. These results also indicate that the average level of accumulated wealth at age 65 is possibly not enough to cover that much money for small but significant population group. Moreover, the difference between quantiles in 1999 and in 2008 indicates that the distribution has shifted to the right, but non proportionally because the $95 \%$ quantile has shifted more than the others. The interpretation is that the $5 \%$ worst cases for men are comparatively much worse in 2008 than they were in 1999.

For women, the quantiles shown in Table 7 are even more extreme than for men. Both in 2008 and in 1999, we estimate that more than $60 \%$ of the women at age 65 will have no lifetime cost on LTC associated to dependence, but $70 \%$ of women have an estimated cost under 69.2 thousand euros, $80 \%$ of women 
Table 7: Lifetime LTC-dependence cost in Spain for people aged 65 years in 2008 and 1999 (in parenthesis)

\begin{tabular}{lcc} 
Quantile & Men & Women \\
\hline $60 \%$ & $0.0(0.0)$ & $0.0(0.0)$ \\
$70 \%$ & $0.0(0.0)$ & $69.2(52.3)$ \\
$80 \%$ & $0.0(0.0)$ & $117.7(95.1)$ \\
$90 \%$ & $111.8(81.0)$ & $251.2(241.3)$ \\
$95 \%$ & $210.9(158.8)$ & $304.7(301.7)$ \\
$99 \%$ & $314.6(296.3)$ & $346.5(345.8)$ \\
\hline \multicolumn{2}{l}{ Cost is expressed in thousand euros }
\end{tabular}

aged 65 would spend less than 117.7 thousand euros and $90 \%$ would spend less than 257.2 thousand euros over their lifetime. All quantiles for women exceed the estimated corresponding quantiles for men. This is what was expected from the data on longevity and prevalence for women. Among women aged 65 years, $10 \%$ have an estimated lifetime cost above 251.1 thousand euros, and for the $5 \%$ of women needing the largest amount of funds for LTC, we estimate that they will require more than 304.7 thousand euros. A group corresponding to $1 \%$ of women aged 65 years have an estimated lifetime cost above 346.5 thousand euros. Again, in aggregated terms this means that, since there were 221,216 women in Spain aged 65 in 2008, over 2,000 women have an estimated LTC cost much above 300 thousand euros. The difference between quantiles in 1999 and in 2008 for women again indicates that the distribution of LTC cost has shifted, but non-proportionally because the highest quantiles have now shifted less than the others. This means that the cost increase has not affected the highest quantiles, but so a small group of women, but instead much pressure is excerpted on a larger group of women, i.e. those having costs above the $70 \%$ quantile.

In total, when taking into account the distribution for men and women, we estimate that more than 4,000 Spanish people aged 65 in 2008 require more than 300 thousand euros each, to cover the cost of LTC over their lifetime. It is the family and the public system that can help those individuals to be able to afford the expenditure.

An additional result is that in 2008 the mean for the distribution estimate for men equals 28.6 (in 1999, it was 25.1) whereas the expectation estimate at age 65 with the actuarial method is 25.6 (it was 22.5 ). For women aged 65 years, in 2008, the mean of the distribution estimate is 61.6 (in 1999, it was 49.3) thousand euros, whereas the actuarial estimate is 53.6 (it was 44.8). We conclude that the mean estimate obtained from the actuarial estimation approach is underestimating the expected lifetime LTC cost given by the distribution method. We note that the distribution approach implemented here may be inducing some positive bias when estimating cost.

The last part of our analysis is directed towards evaluating the impact of the current LTC public system in Spain on the cost distribution and also on the expected LTC costs. We have implemented the simplest scenario, which corresponds to considering that any individual will receive from the public system, 
Table 8: Estimated expected remaining lifetime LTC in dependence individual cost in Spain given current age in 2008 , when allocations from the public system reduce cost

\begin{tabular}{lrrrrrr} 
& \multicolumn{3}{c}{ Men } & \multicolumn{3}{c}{ Women } \\
From age & & $(*) \mathrm{t}$ & Reduction & & $(*)$ & Reduction \\
\hline 65 & 25.6 & 18.3 & $29 \%$ & 56.3 & 39.6 & $30 \%$ \\
70 & 24.5 & 17.2 & $30 \%$ & 53.1 & 37.1 & $30 \%$ \\
75 & 23.5 & 16.3 & $31 \%$ & 49.2 & 33.8 & $31 \%$ \\
80 & 22.8 & 15.4 & $32 \%$ & 43.8 & 29.4 & $33 \%$ \\
85 & 21.8 & 14.2 & $35 \%$ & 36.8 & 24.0 & $35 \%$ \\
90 & 20.0 & 12.5 & $37 \%$ & 28.4 & 18.0 & $37 \%$ \\
95 & 13.8 & 8.2 & $41 \%$ & 15.7 & 9.6 & $39 \%$ \\
100 & 11.3 & 6.3 & $44 \%$ & 9.2 & 5.6 & $40 \%$ \\
105 & 6.7 & 3.6 & $46 \%$ & 4.5 & 2.7 & $40 \%$ \\
\hline Cost is expressed in thousand euros & & & &
\end{tabular}

$(*)$ Allocations from the public LTC system reduce lifetime cost

Table 9: Quantiles of lifetime LTC cost in Spain for people aged 65 years in 2008, when allocations from the public system reduce cost

\begin{tabular}{lrrrrrr} 
& \multicolumn{3}{c}{ Men } & & Women \\
Quantile & & $(*)$ & Reduction & & $(*)$ & Reduction \\
\hline $60 \%$ & 0.0 & 0.0 & - & 0.0 & 0.0 & - \\
$70 \%$ & 0.0 & 0.0 & - & 69.2 & 68.3 & $-1.3 \%$ \\
$80 \%$ & 0.0 & 0.0 & - & 117.7 & 90.5 & $-23.5 \%$ \\
$90 \%$ & 111.8 & 84.9 & $-24.0 \%$ & 251.2 & 157.8 & $-37.2 \%$ \\
$95 \%$ & 210.9 & 136.9 & $-35.1 \%$ & 304.7 & 189.0 & $-38.0 \%$ \\
$99 \%$ & 314.6 & 211.8 & $-32.7 \%$ & 346.5 & 232.6 & $-32.9 \%$ \\
\hline \multicolumn{2}{l}{ Cost is expressed in thousand euros }
\end{tabular}

$(*)$ Allocations from the public LTC system reduce lifetime cost

an allocation corresponding to his or her degree of dependence. For that purpose we have assumed that the real cost of care when accounting for the public support is the one shown on Table 3 minus the average maximum allocation shown on Table 1 for each particular degree. This assumption implies that the yearly cost, once the individual receives support from the public LTC system, would be 8,539,02 euros for those having degree 3, 7,332, 19 euros for those in degree 2 and 13,917.45 euros for those in degree 1, because for this latter group there is no public allowance.

Once the LTC public system is taken into account in the estimates for 2008, the expected LTC using the actuarial approach is reduced and quantiles using the distribution approach also diminish. These comparisons are shown in Tables 8 and 9 . Both the reduction in the expected cost and in quantiles is about $30 \%$, both for men and women.

Our results show even if there is an increasing trend of costs in a decade, that the impact of the current public system funding on the total lifetime cost 


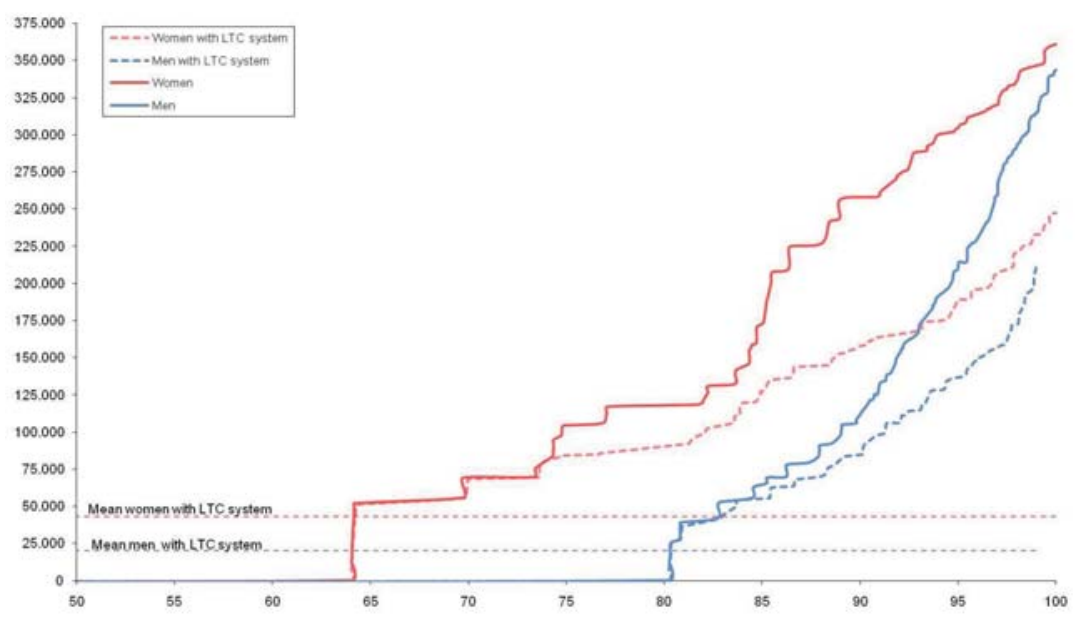

Figure 6: Distribution of LTC costs of dependence in Spain for people aged 65 in 2008 with LTC public system, by gender

distribution at a given age is substantial and reduces the expected cost and the risk of an extreme expenditure. Therefore, we find evidence that the existence of the public LTC system shifts the distribution to the left by reducing the cost of care for many individuals and removes the extremes. This effect is clearly shown in Figure ?? where we see that for people aged 65 the quantile plot presents less extreme cases when the public LTC is in force. So, the curve for men and women when the public LTC system is introduced is significantly below the curve when individuals have to afford all LTC costs. This down shift shows that public coverage acts as a compulsory insurance.

\section{Discussion and conclusions}

As many experts indicate, health and social services must reinforce prevention to extend duration of active life among the elderly. In our analysis we have seen that three factors influence the increase of lifetime LTC cost in the last decade, namely the increase of longevity, a longer duration in the state of dependence and price of care services. Social policies should be devoted to reduce the length of time spent in a state of dependence by promoting active life and they should also dictate rules for the market to provide efficient services with a price change in line with inflation.

Social protection should not set priority on moderate dependence and people non-eligible, who still need care. We have seen that very extreme cases of lifetime LTC cost exist, so establishing a public LTC systems aimed at severe cases reduces the risk of incurring extreme costs. It is then necessary to make people understand that a LTC can only be an efficient risk mitigating tool if targeting the large costs. The welfare system and pensions should take care of more frequent cases with relative low costs.

There are features of the Spanish case reform that have remained beyond the scope of this article. One of them is that there should be more control of the 
assessment scores given to applicants for services from the public system, so that medical and social teams would be equally qualified and their evaluations peer reviewed. There is an urgent need to monitor existing deviations in some regions between the expected number of eligible individuals and the actual number of allocations given. Clarifying vague concepts in the scoring scale is necessary, as well as understanding how, why and when should the official score weights be changed. There are opinions in favor of removing the three level classification of dependence, so that every point given on the measurement scale is linked to some kind of proportional allocation. The main drawback for this proposal is that some services, unlike cash, cannot be assigned points in a proportional manner. In fact, one person may get only one form of care, for instance, a residence. Another disadvantage is that not having a limited number of severity levels makes it more difficult to design public policies aimed to address the worst cases. One more suggestion is to introduce means-tested co-payments, but this can lead to moral hazard, because wealth can be transferred to third-parties in order to obtain public subsidies. In fact this can have a deterrence effect towards extending private insurance, similar to the phenomenon observed in the United States resulting from the way the Medicare system operates, where the market for private LTC coverage has remained very small (Miller et al., 2009).

Our analysis can help design campaigns to promote public awareness and show that the public system should increase assistance in kind, and reduce allocations in cash to be more efficient and target the extreme cases. The calculation of lifetime costs can also help us address sustainability of public funding, in the future years. It may also assist us to define adequate partnership and complementarity between public and private insurance funding, in terms of the impact of public funds on the individual LTC cost distribution.

The LTC insurance market in Spain is still very immature (Pinquet and Guillén, 2008). The possibility to deduct LTC insurance premiums from taxes in conjunction with pension plans has been pointed out as a key driver and it has already been permitted, but to a very limited extend. Currently, market premiums are still expensive. For instance, a 1,000 monthly annuity in the event of full dependence is priced at about 265 euros for a man and 492 euros for a woman age 50 . The market tends to reject this sort of product and would prefer some alternative where at least part of the cumulated insurance premium could be passed on to heirs if no dependence annuity has been received. Otherwise, consumers feel that money going into LTC insurance premiums is lost savings.

Economic recession periods do not favor the development of LTC insurance, but the decrease of house prices shows that if this is the only form of savings then it can be very vulnerable to price fluctuations. In fact, some traditional forms of savings subject to market or liquidity risk may not be a good option to protect against the possibility of high lifetime LTC cost.

We would like to add to our discussion that there are some limitations in our analysis. One is that we have assumed equal mortality rates for all subpopulations of the same gender. This means that we have used two mortality tables, one for men and another for women, but no difference between the mortality of dependent and non-dependent has been assumed. Moreover, our methodology assumes a discrete time framework, which allows for one transition a year between states. Since we have used age groups of one year, we have quite an accurate estimate of the prevalence for every age and so we believe that the loss of precision is rather small. A continuous-time model, like the semi-Markovian 
one (see, D'Amico et al., 2009), with transition probabilities depending on the duration of a given state, would demand a much more complex mathematical setting.

Another limitation in our analysis is that we have only considered LTC costs associated with the definition of dependence in the Spanish legislation. We are indeed aware that people that would be classified as non-dependent by the Spanish scale, may still need some form of care and that including this extended definition of LTC would increase the estimated cost distribution. We have been very restrictive in the definition of care need, and so this is the main reason why our results differ from the ones one would get for the American Medicare LTC cost planning tool, which considers a different definition of severity (Stevenson et al. 2010).

Our results can also be used to show the impact of the current public system funding on the total lifetime cost distribution at a given age. We have concluded that the existence of the public systems shifts the distribution to the left by reducing the cost of care for individuals and removes the extreme cases: This means that the public coverage has the same result as a compulsory insurance.

A final point for discussion is the difference between the two methods used in our presentation. The actuarial method is very straightforward and can be used to compare the expected lifetime LTC cost at different ages, or planning horizons. Its main disadvantage is that only the expected value is predicted, and not the entire distribution. On the other hand, the second method we have used, which is the estimation of the lifetime LTC cost distribution, changes for every given age. Here we have only computed the distribution for people aged 65 years. It is more difficult to compare the distribution than the expectation, but the distribution estimate helps to understand the enormous variability of lifetime LTC cost among a given cohort. Both methods presented in this article can incorporate more sophisticated inflation assumptions compared to the flat rate assumed here and, if necessary, the mortality differences between dependent and non-dependent individuals. An extra feature of the second approach is the possibility to estimate quantiles and probability intervals. The later has not been presented here, but we can predict the probability that lifetime LTC costs fall between two limits.

Our conclusion is that individual lifetime LTC cost prediction due to need of support from others shows significant differences for men and women, and a significantly different rate of growth in the last decade in Spain. We believe that differences in longevity and in prevalence of dependence are the main explanation for the gap between genders. We have also estimated that a relatively small percentage of both men and women at age 65 will incur very high lifetime LTC costs compared to the vast majority of individuals, who will not have a dependence situation during life and therefore will have no LTC cost. This finding is similar to the studies carried out in the United States (Brown and Finkelstein, 2009, Stevenson) and in the United Kingdom (Forder and Fernandez, 2009).

Finally, we have seen that a public system or a compulsory insurance aimed at covering the most extreme situations removes part of the extremes in the cost distribution and, therefore acts as an effective risk reducing mechanism, so that the most risk averse individuals should be the ones more in favor of combining compulsory and voluntary LTC insurance. Most consumers feel that money going into LTC insurance premiums is lost savings, without knowing the size of risk when estimating the LTC cost distribution. We have calculated the risk 
of LTC cost using a quantile and we have seem that the Spanish public LTC system reduces the risk of LTC cost distribution by approximately one third.

\section{References}

Albarran, I., Ayuso, M., Guillén, M. and Monteverde, M. (2005) "A multiple state model for disability using the decomposition of death probabilities and cross-sectional data" Communications in Statistics: Theory and Methods, 24, 9, 2063-2076.

Bermúdez, Ll., Guillén, M. and Solé-Auró, A. (2009) "Scenarios for the impact of immigration in the longevity and dependence of the elderly in the Spanish population[in Spanish]" Revista Española de Geriatría y Gerontología, $44,1,19-24$.

Brown, J.R. and Finkelstein, A. (2008) "The Interaction of Public and Private Insurance: Medicaid and the Long-Term Care Insurance Market" American Economic Review 98, 1083-1102.

Brown, J.R. and Finkelstein (2009) "The Private Market for Long-Term Care Insurance in the United States: A Review of the Evidence" Journal of Risk and Insurance 76, 5-29.

Cairns, A., Blake, D. and Dowd, K. (2008) "Modeling and management of mortality risk: A review" Scandinavian Actuarial Journal 2-3, 79-113.

Castries de, H. (2009) "Ageing and Long-Term Care: Key Challenges in LongTerm Care Coverage for Public and Private Systems" The Geneva Papers on Risk and Insurance 34: 24-34.

Chiang, C.L. (1984) The Life Table and its Applications. Robert E. Krieger Publishing Company. Malabar, Florida.

Crimmins, E., Hayward, M. and Saito, Y. (1994) "Changing Mortality and Morbidity Rates and the Health Status and Life Expectancy of the Older Population" Demography 31, 159-175.

D'Amico, G., Guillén, M. and Manca, R. (2009) "Full backward non-homogeneous semi-Markov processes for disability insurance models: a Catalunya real data application" Insurance: Mathematics and Economics, 45, 2, 173-179.

Esparza Catalán, C. (2010) "Métodos de cálculo de la gravedad de la discapacidad". Madrid, Informes Portal Mayores, $\mathrm{n}^{\circ} 103$ [Published on: 25/06/2010]. jhtt p://www.imsersomayores.csic.es/documentos/documentos/pmmetodos-01.pdf;

Feder J., Komisar H.L., Friedland R.B. (2007) "Long-Term Care Financing: Policy Options for the Future, A Comparative Assessment of Strategies" Long-Term Care Financing Project, Georgetown University.

Fernandez J.L., Forder J., Trukeschitz B., Rokosova M. and McDaid D. (2009) "How can European states design efficient, equitable and sustainable funding systems for long-term care projects for older people?", World Health Organisation, Copenhagen [ISSN: 1997-8073]. 
Forder J. and Fernandez J.L. (2009) "Analysing the costs and benefits of social care funding arrangements in England: technical report", Report to the Department of Health, PSSRU Discussion Paper 2644, Personal Social Services Research Unit.

Gleckman, H. (2010) Long-Term Care Financing Reform: Lessons from the U.S. and Abroad, The Commonwealth Fund, Feb. 2010.

Guillén, M., Nielsen, J.P. and Pérez-Marín, A.M. (2006) "Multiplicative hazard models for studying the evolution of mortality", The Annals of Actuarial Science, 1, 1, 165-177.

Guillén, J. and Pinquet, J. (2008) "Long-term care: risk description of a Spanish portfolio and economic analysis of the timing of insurance purchase", Geneva Papers on Risk and Insurance-Issues and Practice, 33, 659-672.

Guillén, M., Rodríguez, N. and Strassberg, B.A. (2007) "The new responsibilities of social sciences in aging societies. The case of Spain", International Journal of Interdisciplinary Social Sciences, 2, 213-228.

Haberman, S. and Pitacco, H. (1999) Actuarial models for disability insurance. CRC Press, London.

Holdenrieder J. (2006) "Equity and efficiency in funding long-term care from an EU perspective" Journal of Public Health 14: 139-147.

Kessler, D. (2008) "The Long-Term Care Insurance Market" The Geneva Papers on Risk and Insurance-Issues and Practice, 33, 33-34.

Miller, E.A., Mor V. and Clark, M. (2009) "Reforming Long-Term Care in the United States: Findings From a National Survey of Specialists" The Gerontologist, 50, 2, 238-252.

Pinquet, J., Guillén, M. and Ayuso, M. (2009) "Long-Term Insurance: A Case Study" Pravartak-Journal of Insurance and Risk Management, forthcomming.

Pinquet, J., Guillén, M. and Ayuso, M. (2010) "Commitment and Lapse Behavior in Long-Term Insurance: A Case Study" Working Papers HEC, Paris.

Reimat, A. (2009) "Welfare regimes and long-term care for elderly people in Europe". The European Social Model in a Global Perspective. IMPALLAESPAnet Joint conference. March 6-7, 2009.

Solé-Auró, A. and Crimmins, E.M. (2008) "Health of Immigrants in European countries", International Migration Review, 42, 4, 861-876.

Stevenson D.G., Cohen M.A., Tell E.J. and Burwell B. (2010) "The Complementarity of Public and Private Long-Term Care Coverage" Health Affairs, 29 (1): 96-101.

Sullivan, D (1971) "A Single Index of Mortality and Morbidity" HSMHA Health Reports 86, 347-354. 
Wittemberg, R, Sandhu, B. and Knapp, M. (2002) "Funding long-term care: the public and private options". Chapter 10. Funding Health Care: Options for Europe edited by Elias Mosialos et al. 226-249.

\section{Appendix}

Table 10: Weights for BVD calculation in Spain 2010 by age group

\begin{tabular}{|c|c|c|c|c|c|c|}
\hline & \multicolumn{3}{|c|}{ no IADLs } & \multicolumn{3}{|c|}{ with IADLs } \\
\hline Type of activity & $7-10$ & $11-17$ & $18+$ & $7-10$ & $11-17$ & $18+$ \\
\hline Cannot pay attention by looking or listening & & & & 3.106 & 3.23125 & 3.08 \\
\hline $\begin{array}{l}\text { Cannot learn to read, write, count (or calculate), } \\
\text { copy or learn how to handle devices }\end{array}$ & & & & 3.106 & 3.23125 & 3.08 \\
\hline $\begin{array}{l}\text { Cannot perform simple tasks without help or su- } \\
\text { pervision }\end{array}$ & & & & 3.106 & 3.23125 & 3.08 \\
\hline $\begin{array}{l}\text { Cannot perform complex tasks without help or } \\
\text { supervision }\end{array}$ & & & & 3.106 & 3.23125 & 3.08 \\
\hline $\begin{array}{l}\text { Cannot maintain the body in the same position } \\
\text { without help or supervision }\end{array}$ & 5.5 & 5.5 & 4.7 & 1.21 & 1.21 & 1.1 \\
\hline $\begin{array}{l}\text { Cannot change body position without help or su- } \\
\text { pervision }\end{array}$ & 5.5 & 5.5 & 4.7 & 0.99 & 0.99 & 0.9 \\
\hline $\begin{array}{l}\text { Cannot walk or move around the house without } \\
\text { help or supervision }\end{array}$ & 13.4 & 13.4 & 12.3 & 13.2 & 13.2 & 12.1 \\
\hline $\begin{array}{l}\text { Cannot walk or move around outside the house } \\
\text { without help or supervision }\end{array}$ & 12.3 & 9.225 & 9.15 & 14 & 10.5 & 9.674 \\
\hline $\begin{array}{l}\text { Cannot move using transportation as a passenger } \\
\text { without help or supervision }\end{array}$ & & 1.5375 & 1.525 & & 1.75 & 1.6125 \\
\hline Cannot drive without help & & 1,5375 & 1.525 & & 1.75 & 1.6125 \\
\hline $\begin{array}{l}\text { Cannot wash or dry him/herself without help or } \\
\text { supervision }\end{array}$ & 9.6 & 9.6 & 8.8 & 8.7 & 8.7 & 8 \\
\hline $\begin{array}{l}\text { Cannot take care of his/her body without help or } \\
\text { supervision }\end{array}$ & 3.2 & 3.2 & 2.9 & 2.2 & 2.2 & 2 \\
\hline $\begin{array}{l}\text { Cannot use the toilet (urination) without help or } \\
\text { supervision }\end{array}$ & 6.44 & 6.44 & 5.92 & 3.04 & 3.04 & 2.8 \\
\hline $\begin{array}{l}\text { Cannot use the toilet (defection) without help or } \\
\text { supervision }\end{array}$ & 9.66 & 9.66 & 8.88 & 4.56 & 4.56 & 4.2 \\
\hline $\begin{array}{l}\text { Cannot dress or undress him/herself without help } \\
\text { or supervision }\end{array}$ & 12.9 & 12.9 & 11.9 & 12.6 & 12.6 & 11.6 \\
\hline Cannot eat or drink without help or supervision & 18.3 & 18.3 & 16.8 & 10.9 & 10.9 & 10 \\
\hline $\begin{array}{l}\text { Cannot organize or do the shopping or carry the } \\
\text { goods without help or supervision }\end{array}$ & & & 2 & & & 2 \\
\hline Cannot prepare meals without help or supervision & & & 3.6 & & & 3.6 \\
\hline $\begin{array}{l}\text { Cannot do household chores without help or su- } \\
\text { pervision }\end{array}$ & & & 2.4 & & & 2.4 \\
\hline $\begin{array}{l}\text { Cannot follow medical prescriptions without help } \\
\text { or supervision }\end{array}$ & 1.6 & 1.6 & 1.45 & 6 & 6 & 5.5 \\
\hline $\begin{array}{l}\text { Cannot avoid danger in daily lie without help or } \\
\text { supervision }\end{array}$ & 1.6 & 1.6 & 1.45 & 6 & 6 & 5.5 \\
\hline Cannot show feelings. respect or care to others & & & & 0.464 & 0.4084 & 0.3424 \\
\hline Cannot establish or maintain family relationships & & & & 0.464 & 0.4083 & 0.3423 \\
\hline $\begin{array}{l}\text { Cannot establish or maintain relationships or sex- } \\
\text { ual partners }\end{array}$ & & & & 0.464 & 0.4083 & 0.3423 \\
\hline $\begin{array}{l}\text { Cannot establish or maintain a relationship with } \\
\text { friends. neighbours. acquaintances and col- } \\
\text { leagues }\end{array}$ & & & & 1.392 & 1.225 & 1.027 \\
\hline $\begin{array}{l}\text { Cannot establish or maintain a relationship with } \\
\text { subordinates. equal or senior }\end{array}$ & & & & 1.392 & 1.225 & 1.027 \\
\hline
\end{tabular}


WP 2010/11

WP 2010/10

WP 2010/09

WP 2010/08

WP 2010/07

WP 2010/06

WP 2010/05

WP 2010/04

WP 2010/03

WP 2010/02

WP 2010/01

WP 2009/26

WP 2009/25

WP 2009/24

WP 2009/23

WP $2009 / 22$

WP 2009/21

WP 2009/20

WP 2009/19

WP 2009/18

WP 2009/17

WP 2009/16

WP 2009/15

WP 2009/14
"Prediction of the economic cost of individual long-term care in the Spanish population" Bolancé, C ; Alemany, R ; and Guillén M

"On the Dynamics of Exports and FDI: The Spanish Internationalization Process" Martínez-Martín $\mathrm{J}$.

"Urban transport governance reform in Barcelona" Albalate, D ; Bel, G and Calzada, J.

"Cómo (no) adaptar una asignatura al EEES: Lecciones desde la experiencia comparada en España" Florido C. ; Jiménez JL. and Perdiguero J.

"Price rivalry in airline markets: A study of a successful strategy of a network carrier against a low-cost carrier" Fageda, X ; Jiménez J.L. ; Perdiguero , J.

"La reforma de la contratación en el mercado de trabajo: entre la flexibilidad y la seguridad" Royuela V. and Manuel Sanchis M.

"Discrete distributions when modeling the disability severity score of motor victims" Boucher, J and Santolino, $\mathrm{M}$

"Does privatization spur regulation? Evidence from the regulatory reform of European airports . Bel, G. and Fageda, X."

"High-Speed Rail: Lessons for Policy Makers from Experiences Abroad". Albalate, D ; and Bel, G."

"Speed limit laws in America: Economics, politics and geography". Albalate, D ; and Bel, G."

"Research Networks and Inventors' Mobility as Drivers of Innovation: Evidence from Europe" Miguélez, E. ; Moreno, R."

"Social Preferences and Transport Policy: The case of US speed limits" Albalate, D.

"Human Capital Spillovers Productivity and Regional Convergence in Spain", Ramos, R ; Artis, M. ; Suriñach, J.

“Human Capital and Regional Wage Gaps”,López-Bazo,E. Motellón E.

"Is Private Production of Public Services Cheaper than Public Production? A meta-regression analysis of solid waste and water services" Bel, G.; Fageda, X.; Warner. M.E.

“Institutional Determinants of Military Spending” Bel, G., Elias-Moreno, F.

"Fiscal Regime Shifts in Portugal” Afonso, A., Claeys, P., Sousa, R.M.

"Health care utilization among immigrants and native-born populations in 11 European countries. Results from the Survey of Health, Ageing and Retirement in Europe” Solé-Auró, A., Guillén, M., Crimmins, E.M.

"La efectividad de las políticas activas de mercado de trabajo para luchar contra el paro. La experiencia de Cataluña” Ramos, R., Suriñach, J., Artís, M.

"Is the Wage Curve Formal or Informal? Evidence for Colombia” Ramos, R., Duque, J.C., Suriñach, J.

"General Equilibrium Long-Run Determinants for Spanish FDI: A Spatial Panel Data Approach" Martínez-Martín, J.

"Scientists on the move: tracing scientists' mobility and its spatial distribution" Miguélez, E.; Moreno, R.; Suriñach, J.

"The First Privatization Policy in a Democracy: Selling State-Owned Enterprises in 1948-1950 Puerto Rico" Bel, G.

“Appropriate IPRs, Human Capital Composition and Economic Growth” Manca, F. 
WP 2009/13 “Human Capital Composition and Economic Growth at a Regional Level” Manca, F.

WP 2009/12 “Technology Catching-up and the Role of Institutions” Manca, F.

WP 2009/11 “A missing spatial link in institutional quality” Claeys, P.; Manca, F.

WP 2009/10 "Tourism and Exports as a means of Growth” Cortés-Jiménez, I.; Pulina, M.; Riera i Prunera, C.; Artís, M.

WP 2009/09 "Evidence on the role of ownership structure on firms' innovative performance” Ortega-Argilés, R.; Moreno, R.

WP 2009/08 “Por qué se privatizan servicios en los municipios (pequeños)? Evidencia empírica sobre residuos sólidos y agua" Bel, G.; Fageda, X.; Mur, M.

WP 2009/07 “Empirical analysis of solid management waste costs: Some evidence from Galicia, Spain” Bel, G.; Fageda, X.

WP 2009/06 “Intercontinental fligths from European Airports: Towards hub concentration or not?” Bel, G.; Fageda, X.

WP 2009/05 "Factors explaining urban transport systems in large European cities: A cross-sectional approach" Albalate, D.; Bel, G.

WP 2009/04 "Regional economic growth and human capital: the role of overeducation” Ramos, R.; Suriñach, J.; Artís, M.

WP 2009/03 "Regional heterogeneity in wage distributions. Evidence from Spain” Motellón, E.; López-Bazo, E.; El-Attar, M.

WP 2009/02 "Modelling the disability severity score in motor insurance claims: an application to the Spanish case" Santolino, M.; Boucher, J.P.

WP 2009/01 “Quality in work and aggregate productivity” Royuela, V.; Suriñach, J.

WP 2008/16 "Intermunicipal cooperation and privatization of solid waste services among small municipalities in Spain” Bel, G.; Mur, M.

WP 2008/15 "Similar problems, different solutions: Comparing refuse collection in the Netherlands and Spain" Bel, G.; Dijkgraaf, E.; Fageda, X.; Gradus, R.

WP 2008/14 "Determinants of the decision to appeal against motor bodily injury settlements awarded by Spanish trial courts" Santolino, M

WP 2008/13 "Does social capital reinforce technological inputs in the creation of knowledge? Evidence from the Spanish regions" Miguélez, E.; Moreno, R.; Artís, M.

WP 2008/12 “Testing the FTPL across government tiers” Claeys, P.; Ramos, R.; Suriñach, J.

WP 2008/11 "Internet Banking in Europe: a comparative analysis” Arnaboldi, F.; Claeys, P.

WP 2008/10 "Fiscal policy and interest rates: the role of financial and economic integration" Claeys, P.; Moreno, R.; Suriñach, J.

WP 2008/09 "Health of Immigrants in European countries” Solé-Auró, A.; M.Crimmins, E.

WP 2008/08 “The Role of Firm Size in Training Provision Decisions: evidence from Spain” Castany, L.

WP 2008/07 "Forecasting the maximum compensation offer in the automobile BI claims negotiation process" Ayuso, M.; Santolino, M.

WP 2008/06 "Prediction of individual automobile RBNS claim reserves in the context of Solvency II” Ayuso, M.; Santolino, M.

WP 2008/05 "Panel Data Stochastic Convergence Analysis of the Mexican Regions” Carrion-i-Silvestre, J.L.; German-Soto, V. 
WP 2008/04 "Local privatization, intermunicipal cooperation, transaction costs and political interests: Evidence from Spain” Bel, G.; Fageda, X.

WP 2008/03 "Choosing hybrid organizations for local services delivery: An empirical analysis of partial privatization” Bel, G.; Fageda, X.

WP 2008/02 “Motorways, tolls and road safety. Evidence from European Panel Data” Albalate, D.; Bel, G.

WP 2008/01 "Shaping urban traffic patterns through congestion charging: What factors drive success or failure?" Albalate, D.; Bel, G.

WP 2007/19 “La distribución regional de la temporalidad en España. Análisis de sus determinantes” Motellón, E.

WP 2007/18 “Regional returns to physical capital: are they conditioned by educational attainment?” López-Bazo, E.; Moreno, R.

WP 2007/17 "Does human capital stimulate investment in physical capital? evidence from a cost system framework" López-Bazo, E.; Moreno, R.

WP 2007/16 "Do innovation and human capital explain the productivity gap between small and large firms?" Castany, L.; López-Bazo, E.; Moreno, R.

WP 2007/15 "Estimating the effects of fiscal policy under the budget constraint” Claeys, P.

WP 2007/14 "Fiscal sustainability across government tiers: an assessment of soft budget constraints" Claeys, P.; Ramos, R.; Suriñach, J.

WP 2007/13 "The institutional vs. the academic definition of the quality of work life. What is the focus of the European Commission?” Royuela, V.; López-Tamayo, J.; Suriñach, J.

WP 2007/12 "Cambios en la distribución salarial en españa, 1995-2002. Efectos a través del tipo de contrato" Motellón, E.; López-Bazo, E.; El-Attar, M.

WP 2007/11 “EU-15 sovereign governments’ cost of borrowing after seven years of monetary union” GómezPuig, M..

WP 2007/10 "Another Look at the Null of Stationary Real Exchange Rates: Panel Data with Structural Breaks and Cross-section Dependence" Syed A. Basher; Carrion-i-Silvestre, J.L.

WP 2007/09 "Multicointegration, polynomial cointegration and I(2) cointegration with structural breaks. An application to the sustainability of the US external deficit” Berenguer-Rico, V.; Carrion-i-Silvestre, J.L.

WP 2007/08 "Has concentration evolved similarly in manufacturing and services? A sensitivity analysis" RuizValenzuela, J.; Moreno-Serrano, R.; Vaya-Valcarce, E.

WP 2007/07 "Defining housing market areas using commuting and migration algorithms. Catalonia (Spain) as an applied case study” Royuela, C.; Vargas, M.

WP 2007/06 "Regulating Concessions of Toll Motorways, An Empirical Study on Fixed vs. Variable Term Contracts" Albalate, D.; Bel, G.

WP 2007/05 "Decomposing differences in total factor productivity across firm size” Castany, L.; Lopez-Bazo, E.; Moreno, R.

WP 2007/04 "Privatization and Regulation of Toll Motorways in Europe” Albalate, D.; Bel, G.; Fageda, X.

WP 2007/03 "Is the influence of quality of life on urban growth non-stationary in space? A case study of Barcelona" Royuela, V.; Moreno, R.; Vayá, E.

WP 2007/02 “Sustainability of EU fiscal policies. A panel test” Claeys, P.

WP 2007/01 "Research networks and scientific production in Economics: The recent spanish experience" Duque, J.C.; Ramos, R.; Royuela, V. 
WP 2006/10 “Term structure of interest rate. European financial integration” Fontanals-Albiol, H.; Ruiz-Dotras, E.; Bolancé-Losilla, C.

WP 2006/09 "Patrones de publicación internacional (ssci) de los autores afiliados a universidades españolas, en el ámbito económico-empresarial (1994-2004)” Suriñach, J.; Duque, J.C.; Royuela, V.

WP 2006/08 “Supervised regionalization methods: A survey” Duque, J.C.; Ramos, R.; Suriñach, J.

WP 2006/07 “Against the mainstream: nazi privatization in 1930s germany” Bel, G.

WP 2006/06 "Economía Urbana y Calidad de Vida. Una revisión del estado del conocimiento en España" Royuela, V.; Lambiri, D.; Biagi, B.

WP 2006/05 "Calculation of the variance in surveys of the economic climate” Alcañiz, M.; Costa, A.; Guillén, M.; Luna, C.; Rovira, C.

WP 2006/04 "Time-varying effects when analysing customer lifetime duration: application to the insurance market” Guillen, M.; Nielsen, J.P.; Scheike, T.; Perez-Marin, A.M.

WP 2006/03 "Lowering blood alcohol content levels to save lives the european experience” Albalate, D.

WP 2006/02 "An analysis of the determinants in economics and business publications by spanish universities between 1994 and 2004” Ramos, R.; Royuela, V.; Suriñach, J.

WP 2006/01 “Job losses, outsourcing and relocation: empirical evidence using microdata" Artís, M.; Ramos, R.; Suriñach, J. 
$\mathbb{\Phi}|| R|E| A \mid$ 